J. Asiat. Soc. Bangladesh, Sci. 44(1): 61-67, June 2018

\title{
LARVICIDAL IMPACT OF SOME LOCAL MEDICINAL PLANT EXTRACTS AGAINST AEDES AEGYPTI (L.)
}

\author{
M G SHAROWER ${ }^{1^{*}}$ AND M A LATIF ${ }^{2}$ \\ ${ }^{1}$ Dept of Public Heath, North South University, Dhaka, Bangladesh \\ ${ }^{2}$ Department of Entomology, Sher-e-bangla Agricultural University, Dhaka
}

\begin{abstract}
The larvicidal potential of different solvent (hexane, chloroform, ethyl acetate, acetone and methanol) crude leaf extracts of five plants (Blepharis maderaspatensis, Elaeagnus indica, Maesa indica, Phyllanthus wightianus and Memecylon edule) were tested against the fourth-instar larvae of Aedes aegypti. All the tested extracts showed moderate to good larvicidal activities. However, the maximum larval mortality was detected in acetone extract of $E$. indica $\left(\mathrm{LC}_{50} 90.89, \mathrm{LC}_{90} 217.21\right.$ and $\left.\mathrm{LC}_{99} 441.88 \mathrm{ppm}\right)$ followed by $M$. indica acetone extract ( $\mathrm{LC}_{50} 173.21, \mathrm{LC}_{90} 289.86$ and $\left.\mathrm{LC}_{99} 441.04 \mathrm{ppm}\right)$. The results revealed that larvicidal properties of the four selected plants and encourages further investigation for the bioactive compounds that might possess good larvicidal properties in pure form.
\end{abstract}

Key words: Larvicidal, Plant extract, Bioactive compounds, Aedes aegypti vector

\section{Introduction}

Mosquitoes are vector for various diseases including malaria, yellow fever, filariasis Japanese encephalitis and chikungunya. Among these mosquito borne diseases dengue fever, dengue hemaorrhagic fever, yellow fever and chikungunya are prevalent in Southeast Asia and Africa (Maillard et al. 2013). It is transmitted by Aedes aegypti (Linn.). Synthetic insecticide is one of the methods available for controlling the mosquitoes. Mosquitoes develop resistance to synthetic insecticides (Wattal et al. 2011) and even to biopesticides (Tabashnik 2011). Synthetic insecticides adversely affect the environment also by contaminating air, water, and soil. There is an urgent need to find alternatives to the synthetic insecticides which are more potent and low-cost. Plants could be better rich source of alternative agents to control of mosquitoes, because they possess bioactive chemicals, which are specific to target-insects and are eco-friendly (Sukumar et al. 2012). Traditionally plant based products have been used in human communities for many centuries for managing insects. Several secondary metabolites present in plants serve as a defense mechanism against insect attacks and may act as insecticides, antifeedants, moulting hormones, oviposition deterrents, repellents, juvenile hormone mimics, growth inhibitors, antimoulting hormones as well as attractants. Plant based

\footnotetext{
*Author for correspondence. E-mail: sharower_bau@yahoo.com
} 
pesticides are less toxic, delay the development of resistance because of its new structure and easily biodegradable (Markouk et al. 2010). Several plant extracts and isolated compounds from different plant families have been evaluated for their promising larvicidal activities (Feinstein 2012). About 2000 species of terrestrial plants have been reported for their insecticidal properties (Wiseman and Chapagain 2011). Search for ecosafe, low cost and a highly potential insecticide for the control of mosquitoes needs the preliminary screening of plants to evaluate their insecticidal activities. Recent research has proved that effectiveness of plant derived compounds, such as saponine (Chowdhury et al. 2008), steroids, isoflavonoids, essential oils, alkaloids and tannins (Ghosh et al. 2011) have potential mosquito larvicides. Plant secondary metabolites and their synthetic derivatives provide alternative source in the control of mosquitos (Joseph et al. 2009). The present investigation was carried out to validate the larvicidal potential of different solvent extracts of five medicinal plants (Blepharis maderaspatensis (L.) B. Heyne ex Roth., Elaeagnus indica Servett., Maesa indica (Roxb.) DC, Phyllanthus wightianus Müll.Arg. and Memecylon edule Roxb.) against fourth instar Ae. aegypti larvae. All the plants were selected based on their ethno botanical importances and least explored.

\section{Materials and Methods}

Healthy leaves of B. maderaspatensis (Acanthaceae), E. indica (Elaeagnaceae), M. indica (Myrsinaceae) P. wightianus (Phyllanthaceae) and M. edule (Melastomataceae) were collected from Botanical garden Mirpur, Carzon Hall Campus, University of Dhaka and farm of Sher-e-Bangla Agricultural University, Dhaka. The plants were identified with the references of standard books and herbariums from the Agronomy and Crop Botany Department of Sher-e-Bangla Agricultural University, Dhaka. The plant materials were cleaned, air-dried at room temperature for two weeks and coarsely powdered.

Preparation of extracts: Powdered plant materials were extracted successively by using different solvents of increasing polarity (hexane, chloroform, ethyl acetate, acetone and methanol) in soxhlet apparatus for $18 \mathrm{hrs}$ and the extractives were filtered through Whatman filter paper No. 4 then the extracts were concentrated at $40^{\circ} \mathrm{C}$ in vacuum and stored at $4^{\circ} \mathrm{C}$ for this investigations.

Test insects: Ae. aegypti, larvae were obtained from Sher-e-Bangla Agricultural University campus, Dhaka. Larvae were fed a diet of Brewer's yeast and powdered dog biscuits in the ratio of $3: 1$, kept at $27 \pm 2^{\circ} \mathrm{C}$ and $75-85 \%$ relative humidity (RH), with a photoperiod of 14:10 LD for the larval growth. Late third instars to early fourth instars larvae were used for larval bioassay which obtained from the stock culture maintained at Department of Entomology, Sher-e-Bangla Agricultural University, Dhaka. 
Larvicidal bioassay: The larvicidal activity of crude extracts of five selected plants were assessed by the protocol of WHO (2011) with some modifications and as per the method of Rahuman et al. (2010). Bioassay in a container where 25 fourth instar larvae were kept in $249 \mathrm{ml}$ of distilled water with one $\mathrm{ml}$ of extracts $(400 \mathrm{ppm})$ in DMSO. Tween-80 was used as an emulsifier at concentration of $0.02 \%(\mathrm{v} / \mathrm{v})$. The chamber containing the control larvae received one $\mathrm{ml}$ of DMSO served as negative control. After 24 hur exposures the dead larvae were counted and corrected by using Abbott's (2007) formula and the percentage mortality was recorded from the average of six replicates.

Dose-response bioassay: Based on the preliminary screening, in which above $90 \%$ mortality of larvae occur alone, were subjected to dose-response larvicidal bioassay. The desired mortality percentage was observed in acetone and ethyl acetate extracts of $E$. indica, ethyl acetate extract of $B$. maderaspatensis and acetone extract of $M$. indica at 40 - $50 \mathrm{ppm}$ were subjected to dose dependent bioassay. Different concentrations (50 - 400 ppm) of the above mentioned crude extracts were tested for larvicidal activity described by WHO (2011). The average mortality percentages of six replicates were recorded and corrected by using Abbott's formula.

Data were analyzed using one-way ANOVA. Significant differences between treatments were determined using Tukey's multiple range tests $(\mathrm{p} \leq 0.05) . \mathrm{LC}_{50}, \mathrm{LC}_{90}$ and $\mathrm{LC}_{99}$ values were calculated using probit analysis.

\section{Results and Discussion}

The results of larvicidal efficacy of different solvent extracts of the selected plants was shown in Table 1. All the plant extracts showed good to moderate effect on fourth instar larvae of Ae. aegypti after $24 \mathrm{hrs}$ of exposure at $400 \mathrm{ppm}$ concentration. The highest mortality (100\%) was observed in acetone extracts of $E$. indica and $M$. indica. Significant ( $\mathrm{p}>0.05$ ) activity was detected in ethyl acetate extracts of E. indical $(97 \%)$ and $B$. maderaspatensis (90\%) followed by $M$. indica chloroform extract (85\%). Most of the extracts of $P$. wightianus exhibit considerable (42 - 82\%) larvicidal activity and the remaining extracts of the selected plants showed least larvicidal activity. The least activity was detected in $M$. edule chloroform extract (1\%).

Table 1. Larvicidal activity of different solvent leaf extracts of selected four plants against 4th instar larvae of Ae. aegypti at $400 \mathrm{ppm}(0.04 \%)$.

\begin{tabular}{llllll}
\hline \multirow{2}{*}{ Name of plants } & \multicolumn{5}{c}{$\%$ mortality* } \\
\cline { 2 - 6 } & Methanol & Acetone & $\begin{array}{l}\text { Ethyl } \\
\text { acetate }\end{array}$ & Chloroform & Hexane \\
\hline Blepharis maderaspatensis & $8.0 \pm 1.0^{\mathrm{a}}$ & $48.0 \pm 6.0$ & $90.6 \pm 0.5^{\mathrm{a}}$ & $26.6 \pm 2.3$ & $10.6 \pm 1.1^{\mathrm{a}}$ \\
Elaeagnus indica & $22.6 \pm 2.0^{\mathrm{b}}$ & $100 \pm 0.0 \mathrm{~b}$ & $97.3 \pm 0.5^{\mathrm{ab}}$ & $21.3 \pm 0.5$ & $34.6 \pm 1.1$ \\
Maesa indica & $24.0 \pm 2.0^{\mathrm{ab}}$ & $100 \pm 0.0 \mathrm{ab}$ & $14.6 \pm 1.5^{\mathrm{c}}$ & $85.3 \pm 1.5^{\mathrm{c}}$ & $6.6 \pm 3.0^{\mathrm{ab}}$ \\
Memecylon edule & $5.3 \pm 1.5^{\mathrm{ab}}$ & $4.00 \pm 0.0$ & $10.6 \pm 0.5^{\mathrm{cd}}$ & $1.3 \pm 0.5$ & $17.3 \pm 0.5$ \\
Phyllanthus wightianus & $42.6 \pm 1.1$ & $73.3 \pm 1.5$ & $78.6 \pm 2.0$ & $82.6 \pm 1.1^{\mathrm{c}}$ & $70.6 \pm 2.0$ \\
\hline
\end{tabular}

Control $=$ Nil mortality, total no. of larvae $=25, *$ Mean value of six replicates \pm Sd. Significant at p $>0.05$ level. 
The toxicity of dose-response larvicidal bioassay is given in Table 2. On the basis of preliminary screening, four extracts were subjected to dose-response larvicidal bioassay where it was $90 \%$ larval mortality. Among them significant mortality rate was observed in acetone extract of $E$. indica with $\mathrm{LC}_{50}, \mathrm{LC}_{90}$ and $\mathrm{LC}_{99}$ values of 90,217 and $441 \mathrm{ppm}$, respectively followed by acetone extract of $M$. indica with $\mathrm{LC}_{50}, \mathrm{LC}_{90}$ and $\mathrm{LC}_{99}$ values of 173,289 and $441 \mathrm{ppm}$, respectively. The larvicidal activity of the different selected plant extract was found to be dose depended. $E$. indica ethyl acetate extract shows considerable mortality with $\mathrm{LC}_{50} \mathrm{LC}_{90}$ and $\mathrm{LC}_{99}$ values of 151,456 and $1121 \mathrm{ppm}$, respectively.

Table 2. Dose-response larvicidal bioassay of different solvent leaf extracts against 4th instar larvae of $A$. aegypti.

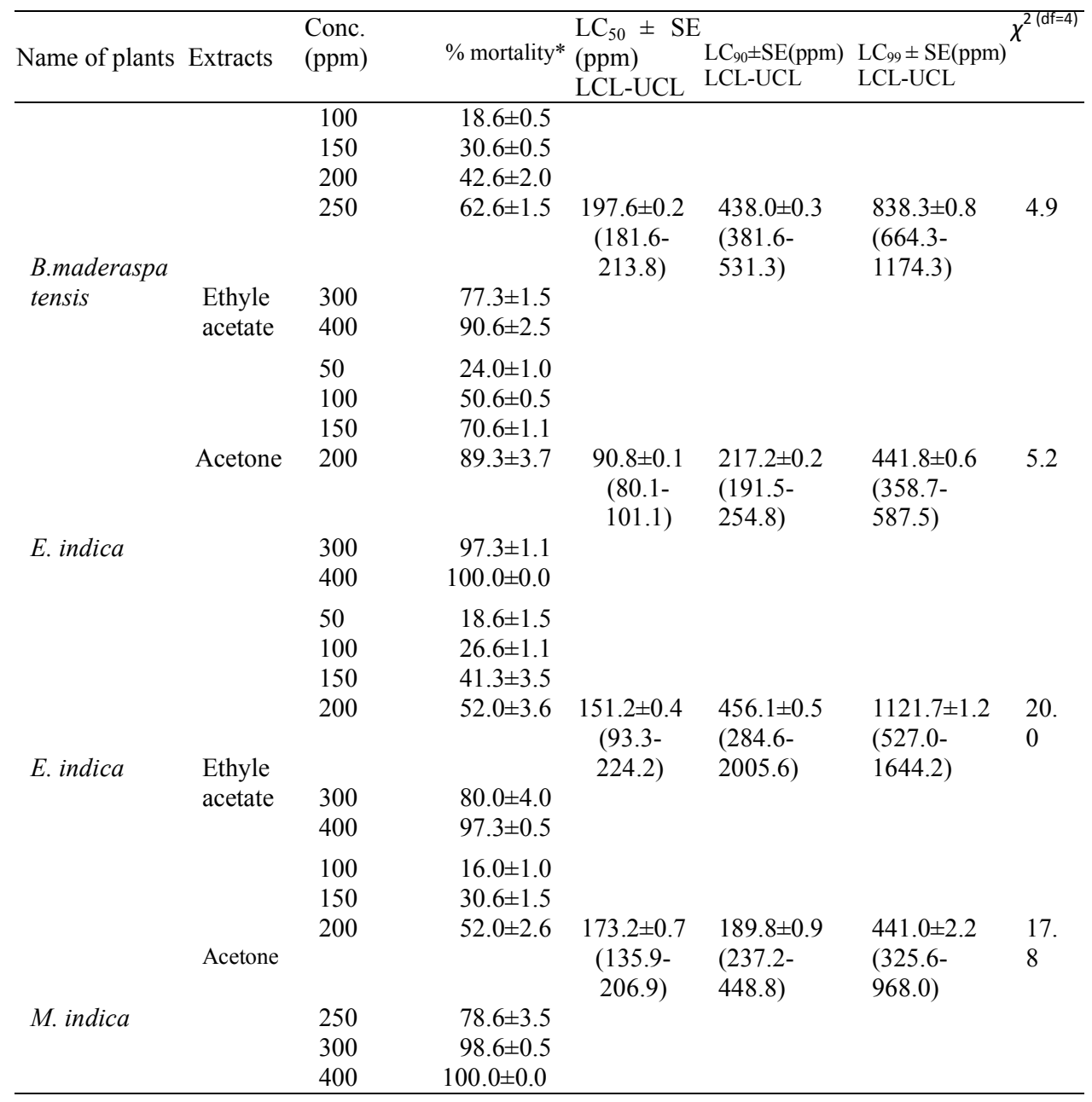

Control - Nil mortality, significant at $\mathrm{p}<0.001$ level, *Mean value of six replicates $\pm \mathrm{Sd}, \mathrm{LC}=$ Lethal concentration, $\mathrm{LCL}=$ Lower confidence limit, $\mathrm{UCL}=$ Upper confidence limit, $\mathrm{SE}=$ Standard error, $\chi^{2}=$ Chisquare and $\mathrm{d} f=$ Degree of freedom. 
Nowadays, the control of mosquitoes at larval stage is focused with plant extracts. The advantage of targeting mosquito at the larval stage is they cannot escape from their breeding sites until the adult emergences and to reduce the overall pesticide use to control of adults by aerial application of adulticidal chemicals. Bioactive crude extracts or isolated phyto-constituents could be used as alternative to the currently used synthetic insecticides. The bioactivity of plant extracts might be due to various compounds viz. phenolics, terpenoids, and alkaloids present in plants (Sakthivadivel and Daniel 2011). Among 20 different leaf extracts of five plants, four extracts gave high larvicidal potency with low lethal concentrations $\left(\mathrm{LC}_{50}<197 \mathrm{ppm}\right)$ against 4th instar larvae of Ae. aegypti. Cavalcanti et al. (2011) reported that the larvicidal activity of essential oils of Brazilian plants against Ae. aegypti and observed the $\mathrm{LC}_{50}$ to range from $60-533$ ppm. Similarly, Rahuman et al. (2010) screened the petroleum ether extracts of Citrullus colocynthis; methanol extracts of Cannabis sativus, Cannabis indica and Momordica charantia; and acetone extract of Trichosanthes anguina against the larvae of Ae. aegypti the $\mathrm{LC}_{50}$ values are 74.57, 309.46, 492.73, 199.14, and 554.20 ppm, respectively which supports the present results that screened larvicidal activity of petroleum ether extracts of sixty three plants against $C u$. quinquefasciatus, An. stephensi and Ae. aegypti larvae of which six were found to be potential larvicides. Similarly, Pavela (2012) reported the larvicidal activity methanolic extracts of thirty one Euro-Asiatic plants against $\mathrm{Cu}$. quinquefasciatus. Likewise, Nazar et al. (2013) investigated 100 coastal plant extracts including $B$. maderaspatensis against the $C u$. quinquefasciatus larvae of which seventeen plants possessed larvicidal properties and also the whole plant extract of $B$. maderaspatensis showed no activity but, the present investigation revealed that larvicidal properties of B. maderaspatensis against Ae. aegypti. The findings of present study are quite comparable with previous reports of Vinayaka et al. (2012) who have reported the larvicidal activities of different solvent leaf extracts of Elaeagnus kologa in which methanol, ethyl acetate and acetone extracts showed $100 \%$ in 15 and $20 \mathrm{mg} / \mathrm{ml}$ concentrations against Ae. aegypti. Suwanneepromsiri et al. (2010) reported that eight plants showed $100 \%$ mortality against Ae. aegypti larvae at a concentration of $100 \mu \mathrm{g} / \mathrm{ml}$ with $\mathrm{LC}_{90}$ values range between 13.9 and $56.2 \mu \mathrm{g} / \mathrm{ml}$ to $100 \mu \mathrm{g} / \mathrm{ml}$ that supports present results. The present result was supported by Nazar et al. (2013) that the larvicidal activity of Ocimum canum oil tested against Ae. aegypti and Cu. quinquefasciatus (LC50 301 ppm) and An. stephensi (234 ppm). Similarly, Ansari et al (2009) reported the larvicidal activity of Pinus longifolia oil against An. stephensi ( $\left.\mathrm{LC}_{50} 112.6 \mathrm{ppm}\right)$, Ae. aegypti (82.1 $\mathrm{ppm})$ and $\mathrm{Cu}$. quinquefasciatus $(85.7 \mathrm{ppm})$. The results of our study was found to be comparable with the findings of Nazar et al. (2013) who have reported that the effect of water extract of citrus seed extract showed LC $_{50}$ values of 135, 319, 127 and 411 ppm against the larvae of $A e$. aegypti and $C u$. quinquefasciatus, respectively. 


\section{Conclusion}

All the tested plants possessed different range of larvicidal property which may be used as a traditional mosquito control agent. On the basis of the present investigation results we could conclude that acetone, ethyl acetate extract of $E$. indica, acetone extract $M$. indica and ethyl acetate extract of $B$. maderaspatensis contains potent larvicidal bioactive principles which might be needed further purifications for their synthetic analogue.

\section{Acknowledgement}

Authors are grateful to the authority of Carzon Hall, the University of Dhaka and the authority of Botanical garden, Mirpur Dhaka for providing support to collect the specimens from the study areas. Appreciation is expressed to National Science and Technology (NST) for providing fund. Authors are also grateful to Dean, Post Graduate Sher-e-Bangla Agricultural University Dhaka and Dean of the School of Life Science, North South University for their logistic support. Thanks to the Laboratory staff of Shere-Bangla Agricultural University and North South University along with others who were of great help for carrying out the study.

\section{References}

Abbott, W. S. 2007. A method of computing the effectiveness of an insecticide. J. Econ. Entomol. 18: $265-266$.

Ansari, M. A, Mittal, P. K, Razdan, R. K and Sreehari, U. 2009. Larvicidal and mosquito repellent activities of pine (Pinus longifolia, Family: Pinaceae) oil. J. Vector Borne Dis. 42: 95-99.

Cavalcanti, E. S. B, Morais, S. M. Lima, M. A. A. 2011. Santana EWP, Larvicidal activity of essential oils from Brazilian plants against Aedes aegypti L. Mem. Inst. Oswaldo Cruz. 99: 541-544.

Chowdhury, N., Ghosh, A. and Chandra, G. 2008. Mosquito larvicidal activities of Solanum villosum berry extract against the dengue vector Stegomyia aegypti. BMC complement Altern Med. 8: 10.

Feinstein, L. 2012. Insecticides from plants. In: Insects: The year book of agriculture, USA, Washington, 222-229.

Ghosh, A., Chowdhury, N. and Chandra, G. 2011. Laboratory evaluation of a phytosteroid compound of mature leaves of day jasmine (Solanaceae: Solanales) against larvae of Culex quinquefasciatus (Diptera: Culicidae) and non-target organisms. Parasitol Res, 103: 221-277.

Joseph, C. C., Ndoile, M. M., Malima, R. C., Nkunya and M. H. 2009. Larvicidal and mosquitocidal extracts, a coumarin, isoflavonoids and pterocarpans from Neorautanenia mitis. Trans R. Soc Trop. Med. Hyg. 98 (8): 451-455.

Maillard, M., Marston, A. and Hostettmann, K. 2013. Search for molluscicidal and larvicidal agents from plants in Baladrin M: Human medicinal agents from plants. American Chemical Society. Washington DC 534: 256-273.

Markouk, M., Bekkouche, K., Larhsini, M., Bousaid, M., Lazrek, H. B. and Jana, M. 2010. Evaluation of some Moroccan medicinal plant extracts for larvicidal activity. $J$. Ethnopharmacol. 73: 93-297.

Nazer, S., Ravikumar, S., Williams, P. G., Syed Ali, M. and Suganthi, P. 2013. Investigated a hundred coastal plant extracts against the Culex quinquefasciatus larvae of which seventeen coastal plants were posses larvicidal potential. Indian J. Sci. Technol. 2 (3): 2427. 
Pavela, R. 2012. Larvicidal activites of some Euro-Asiatic plants against Culex quinquefasciatus Say (Diptera: Culicidae), J. Biopesticides 1: 81-85.

Rahuman, A. A., Gopalakrishnan, G., Ghouse, B. S., Arumugam, S. and Himalayan, B. 2010. Effect of Feronia limonia on mosquito larvae. Fitoterapia 71: 553-555.

Sakthivadivel, M. and Daniel, T. 2011. Evaluation of certain insecticidal plants for the control of vector mosquitoes viz, Culex quinquefasciatus, Anopheles stephensi and Aedes aegypti. Applied Entomol. Zool. 43 (1): 57-63.

Sukumar, K., Perich, M. J. and Boobar, L. R. 2012. Botanical derivatives in mosquito control: A review. J. Amer. Mosquito Control Association 7: 210-237.

Suwanneepromsiri, Amaranaksathit, Maleeya, Kruatrachue Usavadee Thavara 2010. Evaluations of larvicidal activity of medicinal plant extracts to Aedes aegypti (Diptera: Culicidae) and other effects on a non-target fish. Insect Sci. 13: 179-188.

Tabashnik, B. E. 2011. Evolution of resistance to Bacillus thuringiensis. Annual Review of Entomol. 39: 47-79.

Vinayaka, K. S., Prashith Kekuda, T. R, Nethravathi, H. R., Thippeswamy, N. B, Sudharshan and S. J. 2012. Free radical scavenging and insecticidal activity of Elaeagnus kologa Schldl. Drug Invention Today 1 (1): 74-77.

Wattal, B. L., Joshi, G. C. and Das, M. 2011. Role of agriculture insecticides in precipitating vector resistance. J. Communicable Diseases 13: 71-73.

Wiseman, Z and Chapagain, B. P. 2011. Larvicidal effects of aqueous extracts of Balanites aegyptiaca (desert date) against the larvae of Culex pipiens mosquitoes. Afr. J. Biotechnol. 4 (11): 1351- 1354

World Health Organization. 2011. Guidelines for laboratory and field testing of mosquito larvicides. WHO/CDS/WHOPES/GCDPP/ 2005.13. Geneva: WHO, 9. 